\title{
Predictors of Perceived Satisfaction with Subject Selection of Grade 10 Learners in the Free State Province, South Africa: A Quantitative Analysis
}

Dr P Jonck

\author{
Deputy Director: Research and Policy Development, Gauteng Department of Community Safety \\ petrojonck@hotmail.com
}

EH Swanepoel

Central University of Technology, Department of Teacher Education ebenswan@gmail.com

\section{Doi:10.5901/mjss.2014.v5n27p1006}

\begin{abstract}
In light of South Africa's high unemployment rate and restoration of past inequalities, the pivotal role of career guidance is increasingly highlighted to facilitate the match between supply and demand factors in the labour market. This paper examines predictors of the perceived subject satisfaction of 430 Grade 10 learners from 7 secondary schools in the Free State province as an extension to understanding prospective career choice processes. By underscoring the role of Life Orientation and its component of career education, a regression analysis was done to determine the variance in overall subject satisfaction as influenced by service delivery, overall knowledge of career path, personal confidence and the completion of personality inventories (as a moderating variable influencing personal confidence). Pearson's correlation coefficient was used to explore the relationship between the before mentioned variables. The dimensions knowledge of career path and personal confidence were most associated with subject satisfaction, while the completion of personality inventories and service delivery show the weakest relationship.
\end{abstract}

Keywords: Subject selection; Life Orientation; Career Guidance; Regression analysis; Predictors

\section{Introduction}

While the socio-political transformation of post-apartheid South Africa has led to educational reform to restore past inequalities, less than $10 \%$ of secondary school graduates transition to the vocational environment successfully (Horn, 2006). Seeing as affirmative action and policy reformation are characteristic of South Africa's transition period, the emergence of globalization and a technologically driven workforce has brought on an even more complicated process of career planning for prospective graduates (Maree \& Beck, 2004). Against this background career education and guidance plays an increasingly pivotal role in not only the successful transition from secondary schooling to the employment sector (Maree \& Beck, 2004), but also in preparing learners optimally in career planning through their readiness to make adequate subject selection (Bholanath, 2007).

International and national trends underscore the need for schooling programmes that develop learners holistically in order to equip them with the skills to cope with the demands of the 21st century (Prinsloo, 2007). For this reason, South Africa's life skills focus in education is found within the subject Life Orientation, with one of the domains emphasizing developing learners in socio-economic areas to enhance optimal functioning within the democratic environment characteristic of South African society (Jacobs, 2011). Of note is the contextualized underpinning of Life Orientation which places classroom practice parallel to societal level, engaging the learners in a dialogue underscoring their roles within society through the promotion of applicable knowledge and skills (Pillay, 2012). It is aligned with these ideals that learners prepare to make informed subject choices as a means to overcome the economic crisis and unemployment rate (Van de Venter, 2006) and subsequently become lifelong learners within their respective societies (Department of Education, 2011).

A growing body of research indicates that the practical effectiveness of Life Orientation has not led to the desired outcome of societal transformation (Jacobs, 2011). This discrepancy is demonstrated when exploring literature highlighting the inadequate reasoning of students as to their choices of tertiary education (Bholanath, 2007). Rooth (2005) further alluded to the limited impact of Life Orientation facilitators within the career guidance process, reflecting a 
deficiency of training on part of the service delivery agents. However, no specific research could be found indicative of variables underlying the practical influences of career education and the subsequent selection of subjects of learners in the South African context. As career selections are often based on rushed decisions and choices informed by the status quo (Dabula \& Makura, 2013). The sustainability of subject selection and subsequent satisfaction thereof is a pivotal means to future career decision making processes.

Bholanath (2007) stipulates that successful career choices are based on freedom of choice, having alternative options, and being motivated to choose, yet learners do not possess the knowledge or confidence to optimally implement career decision making processes and as such the conditions are not met in practice. As the Life Orientation curriculum aims to empower learners to transition from the classroom to the world of work (Department of Education, 2011), it is vital to explore career education's impact on subject selection, and subsequently to gain a deeper understanding into the variables which influence subject selection satisfaction as a platform to future career selection satisfaction at postsecondary schooling level.

In light of the paucity of research that provides empirical support to verify the effectiveness of Life Orientation with specific reference to career guidance and the world of work as it is referred to the primary aim of the research reported on in this article was to determine the variables that influence subject selection satisfaction based on the Social Cognitive Career Theory which is often used to facilitate the career decision making process.

\section{Theoretical Framework}

The Social Cognitive Career Theory (SCCT) forms a theoretical framework in which self-efficacy is associated with contextual factors and past experiences which are influential agents in the development of interests and career choices (Lindley, 2005). Self-efficacy informs the development of career interests which subsequently leads to prospective career decisions (Schaub \& Tokar, 2004). Research by Jedidiah and Duffy (2012) underscored the individual's perceived capacity to make career choices and the relation thereof to career choice self-efficacy. The study indicated that minority groups found their perception of capacity to make career choices more difficult than majority groups, and may be attributed to factors such as financial or child care barriers. Rottinghaus, Lindley, Green and Borgen (2002) found that the educational environment is significantly associated with career expectations. This is especially relevant when placed within the framework of South Africa's unequal developmental backgrounds and experiences (Coetzee \& Esterhuizen, 2010) and the unequal distribution of resources impacting learning experiences for different groups.

In order to create a framework relevant to the study within the domain of Life Orientation, the Social Cognitive Career Theory (SCCT) was adapted as a means to explore Grade 10 learners' perceptions of career guidance received and the subsequent satisfaction with selected subjects. Figure 1 illustrates how service delivery as part of the subject Life Orientation influences confidence and subject satisfaction, leading to career path knowledge which ultimately facilitates career choice. Career choices is used as an extension in this regard, as the study was conducted on subject choices of Grade 10 learners.

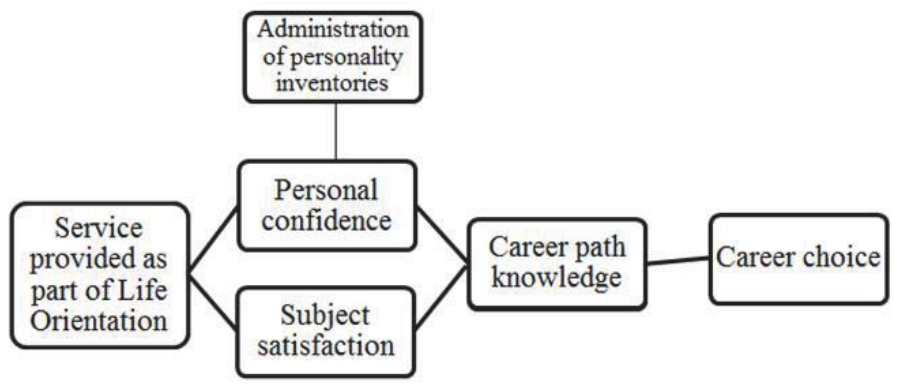

Figure 1: The conceptual model adapted from SCCT (Tang, et al., 2008: 287)

Based on the Social Cognitive Career Theory the question arises how much of the variance in overall satisfaction with subject choices can be explained by service delivery provided by Life Orientation teachers, personal confidence, completion of personality inventories and overall knowledge of career path. The research question was investigated using the following hypotheses: 
Hypothesis 1: Services provided as part of the subject Life Orientation can statistically significantly predict overall satisfaction with subject choices

Pillay (2012) draws on the services of keystone Life Orientation teachers. Specifically related to career guidance, such teachers are specialized in rendering career guidance services to learners. As such, keystone teachings should align with the ideals of instilling learners to make informed choices regarding subjects at schooling level. Jacobs (2007) draw on teacher's reflections of feeling inadequately equipped through training to optimally teach Life Orientation.

It is hypothesised that services delivered during the teaching of Life Orientation will increase personal confidence thus influencing the subject selection process and in turn lead to greater levels of satisfaction. The influence of services provided was underscored to determine the role Life Orientation teachers played in overall satisfaction with subject choices referring to the impact of the Life Orientation Curriculum and the effectiveness thereof. The Department of Education (2013) refereed to 3 dominant factors that influence service delivery during Life Orientation teaching subsuming personal factors such as age, formal training, desire to teach the subject and personal attributes. The second factor referring to interpersonal aspects includes relationship with the learners and support received from stakeholders such as parents and senior staff, while the third factor is based on the availability of resources.

\section{Hypothesis 2: Personal confidence can statically significantly predict overall satisfaction with subject choices.}

Horn (2006) underscores skill-orientated education as an important attribute towards improving self-confidence, which aligns with Life Orientation as the Life Skills faction prevalent in educational settings (Jacobs, 2011). According to the Social Cognitive Career Theory self-efficacy informs the development of career interests which leads to prospective career decisions and is ultimately the impetus behind subject selection in order to pursue said career decisions (Schaub \& Tokar, 2004). Personal confidence is shown to enhance career understanding and buffers the individual from perceiving the world of work as a cycle of low income jobs and unemployment, while a lack thereof may inhibit sufficient career choices (Mubiana, 2010). Drawing on the employability attributes framework of Bezuidenhout (2010) and Coetzee (2010), Potgieter (2012) identifies 8 career-related attributes that underlie sustainable and secure employment. These are career self-management, cultural competence, self-efficacy, career resilience, sociability, entrepreneurial orientation, proactivity and emotional literacy. Supporting the majority of the before mentioned is confidence as a reoccurring attribute in the facilitation of successful career development. It is therefore hypothesise that the personal confidence of the learner will predict subject satisfaction, as the before mentioned literature argues the association between confidence and adequate career choices, and by extension the choices of subjects related thereto.

\section{Hypothesis 3: The variance in overall satisfaction with subject choices was statistically significantly influenced by the} completion of personality inventories.

An influential agent in career choices, and by extension subject choices, is based on knowledge of the self and one's personality (Edwards \& Quinter, 2011). This is reflected through the Curriculum of Life Orientation that draws on the theoretical underpinning of Holland's career choice theory (Department of Education, 2011) in preparing learners for the world of work. The aim of this theory is to align the personality type of the learner with the working environment as a means to increase career satisfaction (Allen, 2005). It is hypothesised that the completion of personality inventories increase personal confidence since it provide the learner with knowledge of themselves and their inherent strengths and weakness therefore influence subject selection satisfaction.

Hypothesis 4: Higher levels of overall satisfaction with subject selection will be statistically significantly associated with overall knowledge of career path.

Eby, Butts and Lockwood (2003) identify knowledge related to the vocational sphere as a predictor of success. This knowledge encompasses insight pertaining to realistic career expectations, personal strengths and weaknesses and specific career related goals. Career information is also fundamental to the decision making process, requiring the individual to have sufficient knowledge in order to make sustainable choices related to the world of work (Mubiana, 2010). Knowledge of the world of work relates to the aim of Life Orientation to promote cognitive growth, and is argued to be positively correlated to ultimate career success ( $\mathrm{Ng}$, Sorensen \& Feldman, 2005). Furthermore, in order to achieve career maturity the individual must be cognitively enabled to make career decisions appropriate to their current challenges and those that subsequently occur at later stages of their lives (Mubiana, 2010). In exploring subject satisfaction as predictor of overall knowledge of career path, it is important to note that both personal knowledge (e.g. strengths, weaknesses, 
likes and dislikes) and career knowledge (e.g. information of different careers, subjects and tertiary level information) is informed through the National Curriculum Statement Policies of Life Orientation (Department of Education, 2011). In drawing future career success to classroom practice, the hypothesis investigates the association between overall perception of knowledge gained and subject selection satisfaction.

\section{Research Methodology}

The research can be described as a quantitative cross sectional design. The study investigated the evaluation of Grade 10 learners in South Africa, Free State province with reference to career guidance provided as part of the subject Life Orientation based on the Social Cognitive Career Theory. No experimental manipulation took place which is indicative of an Ex Post Facto design, with the respondents belonging to different biographical variables prior to data collection. Cross sectional indicates that data gathering took place at a specific point in time with no repeat measures.

\subsection{Procedure and data gathering}

The study commenced with a list of all secondary schools within the Mangaung area in the Free State Province, South Africa. Schools were then randomly sampled by selecting each $5^{\text {th }}$ school, taking into consideration some of the schools declined participation in the Study, the final sample consisted of 7 schools who participated. The schools selected were approached for gatekeeper permission before the questionnaires and consent forms were handed out to the participants, thus reflecting convenient sampling. At the time of the study, the learner population consisted of approximately 640000 (Department of Basic Education, 2012). A total of 430 respondents formed part of the final sample intake, which is found on the 95 confidence level of the population representation, based on a $5 \%$ error margin.

The data collection instrument consisted of The Effectiveness of Career Guidance at secondary school level learner's questionnaire. The instrument consisted of two parts, where the first part gathers quantitative data and the second qualitative responses based on perceptions of various aspects of career guidance. A biographical section gathered information of respondents related to age, socio-economic status, gender and language. The questionnaire consisted of 25 items based on a self-reporting four point Likert scale, where 1 is indicative of 'Always / Very confident / Strongly agree' and 4 represents 'Never / No confidence / Strongly disagree'. The questionnaire covers 5 categories, including service delivery (e.g. My life orientation teacher teaches us study methods to study more effectively), personal confidence (e.g. I am confident that I will be able to choose a study field from a list of potential study fields that I am considering), personality inventory completion (e.g. I am confident that I will be able to choose a study field from a list of potential study fields that I am considering), overall knowledge of career path (e.g. I know what I want to do after school) and lastly overall satisfaction with subject choices (e.g. I have chosen the correct subjects). The theoretical range of scores is between 25 and 100, and all aspects measured through the instrument relate to the theoretical underpinning of the study namely the Social Cognitive Career Development Theory. The reliability of the quantitative part of the instrument was measured at a Cronbach Alpha Coefficient of $a=0.86$, while instrumental validity was performed through exploratory, parallel and confirmatory factor analysis. For the purpose of this study, only the data gathered from the quantitative section of the instrument was utilized.

\subsection{Statistical analysis}

Statistical analysis included standard descriptive statistics to provide a biographical profile of the sample. The hypotheses were tested using a Pearson's product-correlation coefficient, standard multiple regression analysis and an Analysis of Variance (ANOVA). The first mentioned (Pearson's correlation coefficient) was determined to investigate the possible relationships between the different variables. After this a multiple regression analysis were done to determine how much of the variance in overall satisfaction with subject choices can be explained by service delivery, personal confidence, completion of personality inventories and overall knowledge of career path. A one-way ANOVA followed to test whether the services provided by Life Orientation teachers affected overall satisfaction with subject choices. Data processing was done using the SPSS 20.0 program.

\subsection{Ethical consideration}

As the study was based on the responses of minors, ethical clearance was obtained at various levels. The principle requirement was to obtain clearance from the Department of Education to perform research within the Free State 
province. Clearance was also provided through the Faculty Research Committee of the higher education institution of the researcher. At school levels, the principal provided permission to approach the learners, after which consent forms were handed out explaining the study in order to obtain permission from the respondents and their guardians. Permission was obtained from all levels to report findings, while all participants were informed that the study does not entail psychological or physical harm, that participation is voluntary and that subsequent withdrawing from the study could take place at any juncture. .

\section{Results}

To contextualise the findings of the study a synopsis of the biographical profile of the respondents are illustrated in Table 1 below. With reference to the biographical profile of the respondents as indicated in Table 1 , the majority $(n=368)$ classified themselves under the middle socio-economic strata. The total sample also reflects dominantly Afrikaans as language at native level $(n=235)$, with the remainder speaking an indigenous language $(n=165)$ and English $(n=30)$. The majority of the sample $(n=388)$ also falls between the $15-17$ year old age range ascribed to the fact that grade 10 learners were the target population.

Table 1: Demographic profile of the respondents $(n=429)$

\begin{tabular}{|c|l|c|c|c|}
\hline Variable & Level of the variable & $\mathbf{N}$ & $\%$ & Cumulative \% \\
\hline \multirow{3}{*}{ Age } & $12-14$ years & 17 & 4 & 4.0 \\
\cline { 2 - 5 } & $15-17$ years & 388 & 90.4 & 94.4 \\
\cline { 2 - 5 } & Older than 17 & 24 & 5.6 & 100 \\
\hline \multirow{3}{*}{ Gender } & Male & 155 & 36.1 & 36.1 \\
\cline { 2 - 5 } & Female & 274 & 63.9 & 100 \\
\hline \multirow{3}{*}{ Home language } & Indigenous & 165 & 38.4 & 38.4 \\
\cline { 2 - 5 } & English & 30 & 7.0 & 45.3 \\
\cline { 2 - 5 } & Afrikaans & 235 & 54.7 & 100 \\
\hline \multirow{3}{*}{ Socio-economic status } & Low & 22 & 5.1 & 5.3 \\
\cline { 2 - 5 } & Middle & 368 & 87.8 & 93.1 \\
\cline { 2 - 5 } & High & 29 & 6.9 & 100 \\
\hline \multirow{3}{*}{ Type of school } & Predominantly white & 204 & 39.8 & 39.8 \\
\cline { 2 - 5 } & Predominantly black & 55 & 12.8 & 87.2 \\
\cline { 2 - 4 } & Predominantly coloured & & & 100 \\
\hline
\end{tabular}

The relationship between services provided, personal confidence, completion of personality inventories, overall knowledge of career path and overall satisfaction with subject choices were investigated using Pearson's productmoments correlation. As can be seen from Table 2 service delivery has a medium positive $(r=0.39)$ relationship with personal confidence. As service delivery increases so does personal confidence. The completion of personality inventories indicated a weak positive association with both services provided $(r=0.162)$ and personal confidence $(r=$ 0.202). Overall knowledge of career path indicated a weak positive association with services provided $(r=0.205)$, a medium to strong positive association with personal confidence $(r=0.459)$ and a weak relationship with the completion of personality inventories $(r=0.220)$. Thus as personal confidence of the respondent increases so does overall knowledge of career path of the respondent in this case of grade 10 learners. Overall satisfaction with subject choices does not have a correlation with services provided (as could be expected though based on the Social Cognitive Career Theory service delivery influences personal confidence which in turns influence subject satisfaction), but a moderate positive correlation $(r=0.310)$ with personal confidence, a weak positive correlation $(r=0.180)$ and a medium to strong positive correlation with overall knowledge of career path $(r=0.430)$. Based on the results of the Pearson's product-moment correlation discussed previously the question arises how much variance in overall satisfaction with subject choices can be explained by personal confidence, completion of personality inventories, and overall knowledge of career path. 
Table 2: Pearson's product moment correlation

\begin{tabular}{|l|c|c|c|c|c|c|c|}
\hline Variable & Mean & Sd & $\mathbf{1}$ & $\mathbf{2}$ & $\mathbf{3}$ & $\mathbf{4}$ & $\mathbf{5}$ \\
\hline 1. Services provided & 2.50 & 0.549 & - & & & & \\
\hline 2. Personal confidence & 1.82 & 0.474 & $\begin{array}{c}0.390 \\
0.000^{\star \star \star}\end{array}$ & - & & & \\
\hline 3. Personality inventories & 2.19 & 0.858 & $\begin{array}{c}0.162 \\
0.001^{\star \star \star}\end{array}$ & $\begin{array}{c}0.202 \\
0.000^{\star \star \star}\end{array}$ & - & & \\
\hline 4. Knowledge of career path & 1.7 & 0.870 & $\begin{array}{c}0.205 \\
0.000^{\star \star \star}\end{array}$ & $\begin{array}{c}0.459 \\
0.000^{\star \star \star}\end{array}$ & $\begin{array}{c}0.220 \\
0.000^{\star \star \star}\end{array}$ & - & \\
\hline 5. Overall satisfaction with subject choices & 1.61 & 0.718 & $\begin{array}{c}0.042 \\
0.388\end{array}$ & $\begin{array}{c}0.310 \\
0.000^{\star \star \star}\end{array}$ & $\begin{array}{c}0.180 \\
0.000^{\star \star \star}\end{array}$ & $\begin{array}{c}0.430 \\
0.000^{\star \star \star}\end{array}$ & - \\
\hline
\end{tabular}

${ }^{*} p \leq 0.05 ;{ }^{* *} p \leq 0.01 ;{ }^{* * \star} p \leq 0.001$

Table 3: Multiple regression analysis with overall satisfaction with subject choices as dependent variable

\begin{tabular}{|c|c|c|c|c|c|}
\hline \multirow{3}{*}{ Variables } & \multicolumn{4}{|c|}{ Perceived satisfaction with subject choices } & \multirow{3}{*}{$\mathrm{p}$} \\
\hline & \multicolumn{2}{|c|}{ Un-standardised coefficients } & \multicolumn{2}{|c|}{ Standardised coefficients } & \\
\hline & B & Standard error & $\beta$ & $\mathrm{t}$ & \\
\hline Services provided & -0.147 & 0.062 & -0.112 & -2.382 & $0.018^{\star \star}$ \\
\hline Personal confidence & 0.263 & 0.079 & 0.174 & 3.349 & $0.001^{\star \star}$ \\
\hline Completion of personality inventories & 0.071 & 0.037 & 0.085 & 1.889 & 0.060 \\
\hline Knowledge of career path & 0.292 & 0.041 & 0.355 & 7.209 & $0.000^{\star \star}$ \\
\hline$R^{2}\left(R^{2}\right.$ adjusted $)$ & \multicolumn{5}{|c|}{0.209} \\
\hline $\mathrm{R}^{2}$ & \multicolumn{5}{|c|}{0.217} \\
\hline $\mathbf{F}$ & \multirow{2}{*}{\multicolumn{5}{|c|}{$\frac{28.995}{0.000^{* *}}$}} \\
\hline Significance & & & & & \\
\hline
\end{tabular}

Analysing the regression of overall satisfaction with subject choices by introducing all the independent variables simultaneously resulted in a multiple regression correlation of $\left(R^{2}=0.217\right)$ that is significantly different from zero as can be seen in Table 3. Thus the various independent variables in conjunction predict $21.7 \%$ of the variance in overall subject satisfaction. Significant unique contributions of prediction were found for overall knowledge of career path $(\beta=0.355 ; p=$ 0.000 ) which contributed $35.5 \%$ of the variance, followed by personal confidence $(\beta=0.174 ; p=0.001)$ with $17.4 \%$ and lastly services provided $(\beta=-0.112 ; p=0.018$ ) with $11.2 \%$. Completion of personality inventories does not appear to predict overall subject satisfaction significantly. Thus the completion of personality inventories might influence personal confidence which in turns influence overall satisfaction with subject selection. To further investigate the specific influence of services provided on overall subject satisfaction an ANOVA was performed and illustrated in Table 4 below.

Table 4: Influence of service delivery on overall satisfaction with subject choices

\begin{tabular}{|c|c|c|c|c|c|c|}
\hline & Sum of squares & Df & Mean square & Leven's test $(p)^{1}$ & $f$ & $p$ \\
\hline Between groups & 24.974 & 46 & 0.543 & \multirow{3}{*}{2.966} & \multirow{3}{*}{1.061} & \multirow{3}{*}{0.371} \\
\hline Within groups & 195.450 & 382 & 0.512 & & & \\
\hline Total & 220.424 & 428 & & & & \\
\hline
\end{tabular}

${ }^{*} p \leq 0.05 ;{ }^{* *} p \leq 0.01{ }^{1}$ Note: when Leven's test is significant $(p)$, f value and ANOVA $p$ are not reliable

According to Table 4 in isolation services provided by the Life Orientation teacher does not statistically significantly influence grade 10 learners overall satisfaction with subject choices.

\section{Discussion of Results}

In discussing the results, it is noteworthy to draw on the intrinsic and extrinsic associations of the predictors in the perception of subject satisfaction under respondents. Pearson Product Coefficient reflects a medium to strong positive association between the intrinsic dimensions of overall knowledge of career path and personal confidence $(r=0.459)$, with both before mentioned dimensions being weakly associated with services provided and the administration of 
personality inventories. Both these dimensions furthermore reflect associations with subject satisfaction, with personal confidence $(r=0.310)$ and overall knowledge of career path $(r=0.430)$ being positively correlated thereto. With regard to these findings, hypothesis 2 and hypothesis 4 is accepted in that personal confidence statistically significantly predict overall satisfaction with subject choices personal confidence $(\beta=0.174 ; p=0.001)$ with $17.4 \%$ of the variance as yielded by the results of the multiple regression analysis. Higher levels of overall knowledge of career path is statistically significantly associated with overall satisfaction with subject choices $(r=0.430)$.

The before mentioned findings are supported by the research of Debula and Makura (2013) who found that a lack of self-knowledge and self-efficacy influence South African learners in making uninformed decisions regarding career choices. The importance of fostering these attributes is reflected through Brown (2002) postulating that individuals who view themselves as competent will form enduring interests in activities in anticipation of positive outcomes. As such, learners who perceive themselves as confident and having sufficient knowledge will engage better at subject level with greater levels of subject satisfaction. As subjects are selected during grade 9, these two attributes reflect a critical focus in ensuring learner engagement at later stages of the Further Education and Training Phase, and subsequently choices regarding further study and careers.

Hypothesis 3 is rejected as the variance in overall subject satisfaction is not statistically significantly influenced by the completion of personality inventories with $8.5 \%$ of the variance. It is important to note that teachers are not allowed to administer and interpret personality inventories, as these instruments are reserved for use by qualified psychologists. As such, the financial restraints of administering such tests may not be feasible at all schools. Furthermore, while the administration of personality inventories may provide insight into subject electives, it reflects positive weak associations with overall knowledge $(r=0.220)$ and personal confidence $(r=202)$. Edwards \& Quinter (2011) draw on the importance of self-knowledge and one's personality in making effective career choices. While teacher's cannot administer personality inventories to engage in the aforementioned, the curriculum of Life Orientation utilizes the theory of Holland's career choices (Department of Education, 2011) as a means to establish a framework within which to prepare learners to make subject choices.

This however depends on the knowledge of the theory on part of the teacher's and the manner in which the curriculum is implemented at classroom level. In line with the findings of Jacobs (2007), teachers feel inadequately trained to optimally teach Life Orientation, and as such services rendered is often not in accordance with sufficient coverage of information to instil enduring skills in learners. The results of this study reflected that services provided have a positive significant association with self-confidence $(r=0.39)$, but a weak association with overall knowledge $(r=$ 0.205). Hypothesis 2 is in turn rejected. Factors beyond the services of the teacher that influence career development can be attributed to the learner's perceptions of parental security (Germeijs \& Verschueren, 2009). Parents must in turn be incorporated as cornerstone stakeholders in the process of career education. Other factors would include the individual nature of guidance each learner receives in order to enhance their understanding of themselves and the world of work (Mittendorf, den Brok and Beijaard, 2010). The aforementioned underscores the influences of Life Orientation service delivery (Department of Education, 2013), in that parental support, teacher-learner relationship and availability of resources are dominant factors in determining the quality of services provided.

The findings support the research of Bholanath (2007) in preparing learners to face the increasing challenges of the vocational environment with a perspective of motivation and the ability to perceive themselves as proactive agents who are able to make free choices. A more specialized approach to classroom practice is called for in which educators are familiar with the theories underpinning career education, which aligns with Jacobs' (2011) findings that teachers often perceive themselves as inadequate to teach within the realms of Life Orientation. As could be established through previous research, these findings have not yet been published, and contributes to current research in identifying factors that influence subject selection and in turn engagement at subject level as a reflection of future career decisions. The before mentioned is in line with Life Orientation's aim to foster attributes in learners that will allow them to become proactive citizens with a sense of self and their respective roles within the communities (Department of Basic Education, 2011).

Based on the results and the discussion thereof the use of the Social Cognitive Career Theory as a theoretical framework that can be used to underpin service delivered as part of the subject Life Orientation is supported.

\section{Conclusion and Recommendations}

The results obtained through this study underlines the importance of fostering attributes at intrinsic level in order to ensure subject satisfaction of learners after subject selection takes place. The role of the Life Orientation teacher in the realm of career guidance is thus underscored in providing knowledge associated with future career paths and the 
advancement of personal confidence in order to ensure a pro-active learner-centred environment. Satisfaction with subject choices implicates learner engagement and ultimately the choices of future career paths, and as such it is critical to instil applicable knowledge of how these subject choices will be of relevance to future study and employment decisions. As the modern vocational environment is underscored by dynamic changes and uncertainty, the attribute of personal confidence proves valuable in allowing learners to perceive themselves as capable to be flexible in the wake of change. It is in line with this that the connection between knowledge of future career paths and self-confidence proves valuable. The fostering of self-confidence is especially important when drawn to the timeframe within which learners are expected to make subject choices. In South Africa learners do so in Grade 9, while perspectives and expectations can change during Grade 10 to 12 . The attribute of self-confidence thus ensures that the learner will be able to perceive satisfaction with their choices at later stages and remain engaged in the wake of changes regarding their goals and expectations.

The study provides valuable insight into factors that can predict subject selection satisfaction. The effectiveness of Life Orientation has been questioned by many and scrutinized within a qualitative framework, while how service delivery can be effective within career education is largely unknown.

It is recommended that Life Orientation teachers received more specialized training using the theoretical frameworks associated with career guidance, specifically Holland's career choice framework. As teachers are not permitted to administer personality inventories to learners and such inventories create financial restrictions for certain schools, the manner in which the teachers utilize such theories at classroom level becomes of pivotal importance. As career education forms one pillar of a holistic programme aiming to develop learners, the importance of incorporating various stakeholders in the process is underscored. Of note are the limitations of the study. As the study was conducted within the Free State region of South Africa, care should be taken when generalizing the results to other areas. It is thus further recommended that these findings be researched in other areas to determine the effectiveness of service deliver, knowledge of career path, personal confidence and personality inventory administration as predictors of subject satisfaction at secondary schooling level.

\section{References}

Allen, L.J. (2005). The appropriateness of Holland's Interest code typology for South African field guides. (Masters Dissertation), Nelson Mandela Metropolitan University, Port Elizabeth.

Bezuidenhout, M. (2010). The development of an instrument to measure employability of students: A pilot study. Unpublished draft research proposal. Department of Human Resourcse Management, University of Pretoria.

Bholanath, S. 2007. Effects of career guidance on grade 9 learner's readiness to make career choices. (Master's Dissertation). University of Zululand, South Africa.

Brown, D. (2002). Career choice and development (4th ed.). San Francisco, CA: Jossey-Bass.

Coetzee, M. (2010). Psychological career resources of working adults: A South African Survey. SA Journal of Industrial Psychology, 34(2), 10-20.

Coetzee, M., \& Esterhuizen, K. (2010). Psychological career resources and coping resources of the young unemployed African graduate: An exploratory study. South African Journal of Industrial Psychology, 36(1), 1 - 9. 10.4102/sajip.v36i1.868

Dabula, P., \& Makura, A.H. (2013). High school student's perception of career guidance and development programmes for University access. International Journal for Educational Science, 5(2), 89-97.

Department of Basic Education. (2011). Curriculum and Assessment Policy Statement Grades 7-9: Life Orientation. Government Printing Work, South Africa, Pretoria.

Department of Education. (2013). School-based responses for sexuality education and HIV prevention: Educators' delivery of the Life Orientation Programme in 16 South African secondary schools. SA AIDS Conference, Durban.

Eby, L. T., Butts, M., \& Lockwood, A. (2003). Predictors of success in the era of the boundaryless career. Journal of Organizational Behavior, 24(6), 689-708.

Edwards, K., \& Quinter, M. (2011). Factors influencing students career choices among secondary school students in Kisumu municipality, Kenya. Journal of Emerging Trends in Educational Research and Policy Studies, 2(2), 81-87.

Germeijs, V., \& Verschueren, K. (2009). Adolescents' Career Decision-Making Process: Related to Quality of Attachment to Parents?. Journal of Research on Adolescence, 19(3), 459-483.

Horn, G. (2006). Educational solutions to improve the employability of senior high school learners. South African journal of education, 26(1), p-113.

Jacobs, A. 2011. Life Orientation as experienced by learners: a qualitative study in North-West Province. South African Journal of Education, 31(2), 212 - 223. http://www.sajournalofeducation.co.za/index.php/saje

Jadidian, A., \& Duffy, R. D. (2011). Work Volition, Career Decision Self-Efficacy, and Academic Satisfaction: An Examination of Mediators and Moderators. Journal of Career Assessment, 1069072711420851.

Lindley, L. D. (2005). Perceived barriers to career development in the context of social cognitive career theory. Journal of Career 
Assessment, 13(3), 271-287.

Maree, J. G., \& Beck, G. (2004). Using various approaches in career counselling for traditionally disadvantaged (and other) learners: some limitations of a new frontier. South African Journal of Education, 24(1), p-80.

Mittendorf, K., Den Brok, P., \& Beijaard, D. (2010). Career conversations in vocational schools. British Journal of Guidance and Counseling, 38(2), $143-165.10 .1080 / 03069881003601007$

Mubiana, P.B. (2010). Career maturity, career knowledge, and self-knowledge among psychology honours students: an exploratory study. Unpublished Masters Dissertation, University of Pretoria, Pretoria.

Ng, T. W., Eby, L. T., Sorensen, K. L., \& Feldman, D. C. (2005). Predictors of objective and subjective career success: A metaanalysis. Personnel psychology, 58(2), 367-408.

Pillay, J. (2012). Keystone Life Orientation (LO) teachers: implications for educational, social, and cultural contexts. South African Journal of Education,32(2), 167-177.

Potgieter, I. (2012). The relationship between the self-esteem and employability attributes of postgraduate business management students: original research.SA Journal of Human Resource Management, 10(2), 1-15.

Prinsloo, E. (2007). Implementation of life orientation programmes in the new curriculum in South African schools: perceptions of principals and life orientation teachers. South African Journal of Education, 27(1), 155-170. http://www.sajournalofeducation. co.za/index.php/saje

Rooth, E. (2005). An investigation of the status and practice of Life Orientation in South African schools in two provinces (Doctoral Thesis). University of the Western Cape, South Africa.

Rottinghaus, P. J., Lindley, L. D., Green, M. A., \& Borgen, F. H. (2002). Educational aspirations: The contribution of personality, selfefficacy, and interests. Journal of Vocational Behavior, 61(1), 1-19.

Schaub, M., \& Tokar, D. M. (2005). The role of personality and learning experiences in social cognitive career theory. Journal of Vocational Behavior,66(2), 304-325.

Van de Venter, A.M. (2006). Grade nine learners' experiences of career counselling at school. (Masters Dissertation). University of South Africa, Pretoria. 